Int. J. Electrochem. Sci., 16 (2021) Article ID: 210636

International Journal of

ELECTROCHEMICAL

SCIENCE

www.electrochemsci.org

\title{
Deposition Mechanism and Corrosion Resistance of Ni- Graphene Composite Coatings Prepared by Pulse Electrodeposition
}

\author{
Bingying Wang ${ }^{1}$, Yongmin Zhao ${ }^{1}$, Zhi Qin ${ }^{1}$, Yige Liu ${ }^{1}$, Enyang Liu ${ }^{1, *}$, FengYang $^{2}$, Shouqin Li $^{2}$ \\ ${ }^{1}$ School of Materials Science and Engineering, China University of Petroleum (East China), Qingdao \\ 266580, China \\ ${ }^{2}$ Dongxin Oil Production Plant, Shengli Oilfield Company SINOPEC, Dongying 257094, China \\ "E-mail: enyangliu@ 126.com
}

doi: $10.20964 / 2021.06 .54$

Received: 16 February 2021 / Accepted: 10 April 2021 / Published: 30 April 2021

\begin{abstract}
By adding graphene oxide (GO) to a Watt-type plating solution, a Ni-graphene (G) composite coating was prepared on a N80 steel substrate. Raman and FT-IR spectroscopy were performed to characterize the successful preparation and reduction of graphene oxide. The variation in the morphology of the composite coatings with changes in the average current density, rotation angle of cathode, and concentration of graphene oxide was examined using SEM and EDS analyses. An electrochemical corrosion test was used to study the effect of graphene oxide concentration on the corrosion resistance of composite coatings. A mechanism describing the action of the average current density and rotation angle of cathode during the codeposition process of Ni-G was proposed. It was found that the electrodeposition can be affected by the current density and rotation angle of cathode, confirming that the mechanism of Ni-G composite electrodeposition is controlled by both an electrochemical mechanism and a mechanical stirring mechanism. In addition, we proposed the mechanism of Ni-G composite electrodeposition.
\end{abstract}

Keywords: Ni-G composite coating; Pulse electrodeposition; Corrosion resistance; Deposition mechanism; Graphene oxide

\section{$\underline{\text { FULL TEXT }}$}

(C) 2021 The Authors. Published by ESG (www.electrochemsci.org). This article is an open access article distributed under the terms and conditions of the Creative Commons Attribution license (http://creativecommons.org/licenses/by/4.0/). 